\title{
A mouse model to study the C-terminal regulation of Cav1.3 L-type calcium channels
}

\author{
Anja Scharinger ${ }^{1}$, Florian Hechenblaikner ${ }^{1}$, Gabriella Bock$^{1}$, Mathias Gebhart ${ }^{1}$, Kai Schönig $^{2}$, Dusan Bartsch², \\ Anupam Sah ${ }^{1}$, Nicolas Singewald ${ }^{1}$, Martina J Sinnegger-Brauns ${ }^{1}$, Jörg Striessnig ${ }^{1^{*}}$ \\ From 18th Scientific Symposium of the Austrian Pharmacological Society (APHAR). Joint meeting with the \\ Croatian, Serbian and Slovenian Pharmacological Societies. \\ Graz, Austria. 20-21 September 2012
}

\section{Background}

$\mathrm{Ca}_{V} 1.3$ voltage-gated L-type $\mathrm{Ca}^{2+}$ channels (LTCCs) play an important role for hearing, cardiac pacemaking and neuronal excitability. The C-terminus of $\mathrm{Ca}_{\mathrm{v}} 1.3$ tightly controls channel gating by an intramolecular protein interaction involving two putative $\alpha$-helices (termed PCRD, DCRD), which form a C-terminal modulatory mechanism (CTM) only in full-length $\mathrm{Ca}_{\mathrm{V}} 1.3$ variants. In short $\left(\mathrm{Ca}_{\mathrm{V}} 1.3_{42 \mathrm{~A}}\right.$ and $\left.\mathrm{Ca}_{\mathrm{V}} 1.3_{43 \mathrm{~S}}\right) \mathrm{Ca}_{\mathrm{V}} 1.3 \alpha 1$ subunit splice variants CTM is absent which leads to profound changes in channel gating: activation occurs at more negative voltages and $\mathrm{Ca}^{2+}$-dependent inactivation (CDI) is faster.

\section{Methods}

We quantified $\mathrm{Ca}_{\mathrm{V}} 1.3$ splice variants by $\mathrm{qPCR}$ analysis and transcript scanning, using different mouse tissues. To assess the physiological relevance of CTM, we generated a mutant mouse strain in which CTM function is disrupted by an HA-tag $\left(\mathrm{Ca}_{\mathrm{V}} 1.3-\mathrm{DCRD}{ }^{\mathrm{HA} / \mathrm{HA}}\right.$ mice). We used antiHA antibodies to detect the expression of the HA-tagged full length channel by Western blot analysis.

\section{Results}

The short variants $\mathrm{Ca}_{\mathrm{V}} 1.3_{42 \mathrm{~A}}$ (highest relative abundance in substantia nigra (SN) and ventral tegmental area (VTA)) and $\mathrm{Ca}_{\mathrm{V}} 1.3_{43 \mathrm{~S}}$ are both less abundant in mouse brain indicating that the full length form $\mathrm{Ca}_{\mathrm{V}} 1.3_{\mathrm{L}}$ comprises the most abundant form (about $50 \%$ of all transcripts). In mouse heart short transcripts are rare and $\mathrm{Ca}_{\mathrm{V}} 1.3_{\mathrm{L}}$ represents about $90 \%$ of all known transcripts.

\footnotetext{
* Correspondence: joerg.striessnig@uibk.ac.at

'Department of Pharmacology and Toxicology, Institute of Pharmacy, and Center for Molecular Biosciences Innsbruck, University of Innsbruck, 6020 Innsbuck, Austria

Full list of author information is available at the end of the article
}

$\mathrm{Ca}_{\mathrm{V}}$ 1.3-DCRD ${ }^{\mathrm{HA} / \mathrm{HA}}$ mice contain a homozygous interruption of the CTM by disrupting the DCRD helix with an HA-tag. We show that this induces "short" gating properties in this mutant full-length variant. Homozygous mice are viable and display no gross anatomical and functional abnormalities. Expression of the HA-tagged full-length channel could be detected in mouse whole brain membrane preparations. Heterozygous mice show no overt differences in locomotor activity during daytime.

\section{Conclusions}

We have successfully generated a mouse model which will enable us to study the physiological role of CTM function in vivo. It mimics the (permanent) pharmacological inhibition of CTM function and will thus allow predictions about its potential as a new drug target. Furthermore, the HA-tagged $\alpha 1$ subunit will provide a tool to specifically determine the expression of $\mathrm{Ca}_{\mathrm{V}} 1.3_{\mathrm{L}}$ channels with antiHA antibodies in mouse tissues.

\section{Acknowledgements}

Supported by the Austrian Science Fund project SFB f44, the EC project MRTN-CT-2006-35367 ("CavNet"), FWF 20670 and the University of Innsbruck.

\section{Author details \\ 'Department of Pharmacology and Toxicology, Institute of Pharmacy, and Center for Molecular Biosciences Innsbruck, University of Innsbruck, 6020 Innsbuck, Austria. ${ }^{2}$ Department of Molecular Biology, Central Institute of Mental Health, University of Heidelberg, 68159 Mannheim, Germany.}

Published: 17 September 2012

doi:10.1186/2050-6511-13-S1-A50

Cite this article as: Scharinger et al: A mouse model to study the

C-terminal regulation of Cav1.3 L-type calcium channels. BMC

Pharmacology and Toxicology 2012 13(Suppl 1):A50.

\section{Biomed Central}

(C) 2012 Scharinger et al; licensee BioMed Central Ltd. This is an Open Access article distributed under the terms of the Creative Commons Attribution License (http://creativecommons.org/licenses/by/2.0), which permits unrestricted use, distribution, and reproduction in any medium, provided the original work is properly cited. 